\title{
Expression and Function of Renal Organic Anion Transporters in Cholestasis
}

\author{
Anabel Brandoni and Adriana Mónica Torres \\ Area Farmacología. Facultad de Ciencias Bioquímicas y Farmacéuticas \\ Universidad Nacional de Rosario \\ Argentina
}

\section{Introduction}

Acute jaundice due to bile duct obstruction is defined as the retention of bile and bile components. Kidney and liver are largely responsible for inactivation and excretion of drugs, including organic anions, and other chemicals. In obstructive jaundice, adaptive mechanisms may permit urinary excretion of those potentially toxic compounds that could not be eliminated by the liver because biliary transport is impaired (Reichen \& Simon, 1988; Klaassen \& Aleksunes, 2010; Hagenbuch 2010).

A large and diverse number of organic, or weak organic acids that exist as anions at physiological $\mathrm{pH}$, are secreted by mammalian renal tubules principally along the proximal portion of the nephron. Although this system secretes a number of endogenous compounds, it is generally accepted that is particularly important in secreting numerous exogenous compounds, including pharmacologically active substances, industrial and environmental toxins, and plant and animal toxins (Wright \& Dantzler, 2004; G. Burckhardt \& Pritchard, 2000). The renal organic anion transport plays a critical role, in protecting against the toxic effects of these anionic substances, by removing them from the blood principally via the organic anion transport mechanisms found in the apical and basolateral membrane of renal epithelial cells. Several carrier proteins have been cloned and are functionally characterized from both membrane domains of rat kidneys (ElSheikh et al., 2008; Wright \& Dantzler, 2004). Defining the modifications on the expression of these transporters is important, both to understand the cholestatic process and to identify potential therapeutic targets.

Cholestasis has been shown to alter the transport of bile salts and other organic anions (Denk et al., 2004; Klaassen \& Aleksunes, 2010). The modulation in the expression of renal organic anion transporters constitutes a compensative mechanism to overcome the hepatic dysfunction in the elimination of organic anions.

This chapter reviews our current knowledge of the significant roles played by these transporters in organic anions elimination, focusing particularly in their renal expression and in the mechanisms involved in the regulation of their expression and function in extrahepatic cholestasis. 


\section{Organic anion transporters}

The expression and function of several organic anion transporters in kidneys from rats with obstructive cholestasis will be reviewed. These transport proteins are listed below:

- $\quad$ Organic Anion Transporter 1 (Oat1)

- $\quad$ Organic Anion Transporter 3 (Oat3)

- $\quad$ Bilitranslocase (BTL)

- $\quad$ BSP/Bilirubin Binding Protein (BBBP)

- $\quad$ Sodium dependent Bile Salt Transporter (ASBT)

- $\quad$ Organic Anion Transporting Polipeptide 1 (Oatp1)

- Multidrug Resistance Protein 2 (Mrp2)

Oat1, Oat3, BTL and BBBP are expressed in the basolateral membranes. BBBP is also expressed in apical membrane, together with ASBT, Oatp1 and Mrp2. Their membrane localization is shown in Figure 1.

\section{Organic anions renal secretion}

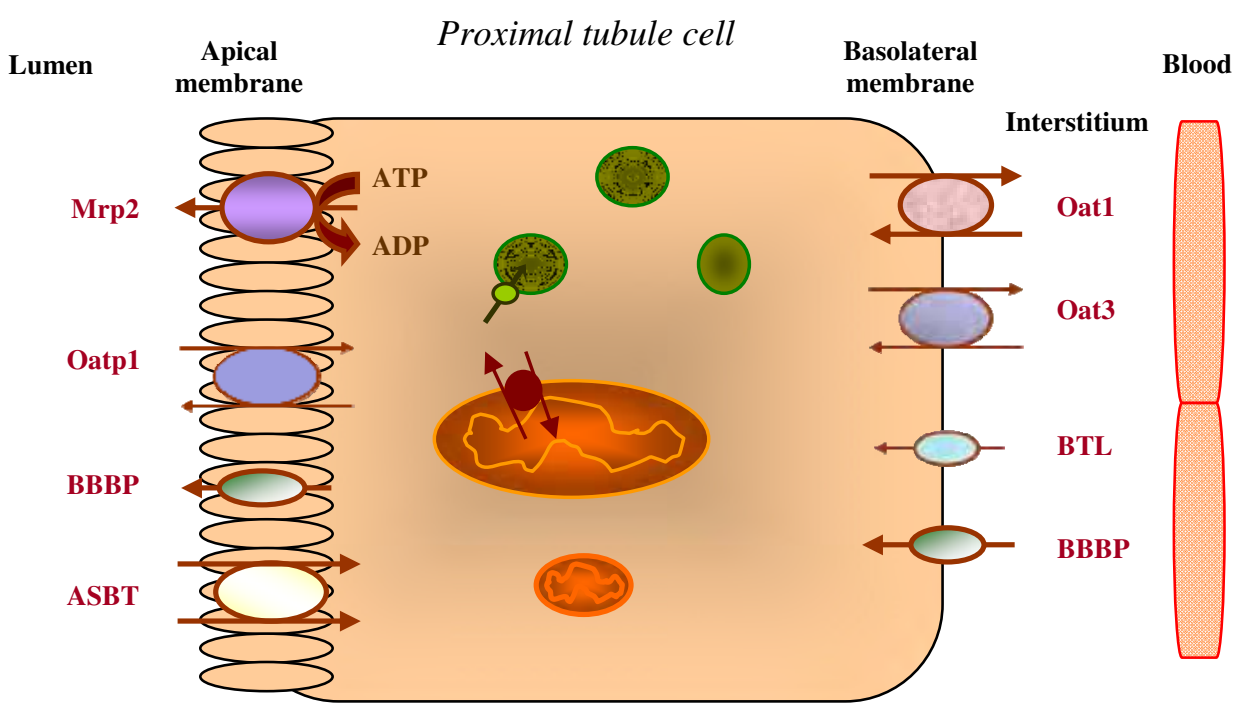

Fig. 1. Organic anion transporters in proximal renal tubule cell. For proteins abbreviations see the text.

\subsection{Oat1}

Organic anion transporter 1 (Oat1) is a key organic anions/a-ketoglutarate exchanger in the energetically linked basolateral entry of organic anions into the proximal tubule cells of the kidneys (Tojo et al., 1999; Kojima et al., 2002). Its substrate selectivity is markedly broad. 
Oat1 is expressed predominantly in the kidneys and weakly in the brain. Oat1 couples organic anions entry to dicarboxylate exit (Sweet, 2005; Torres et al., 2008; Brandoni \& Torres, 2010; G. Burckhardt \& B.C. Burckhardt, 2011). This protein has been immunolocalized to the basolateral surface of the proximal tubule. Oat1 mediates the transport of many compounds (dicarboxylates, nucleotides, prostaglandins, antivirals, loop and thiazide diuretics, $\beta$-lactam antibiotics, non-steroidal anti-inflammatory drugs, including the prototypical substrate of the classical pathway, para-aminohippurate (PAH) (Brandoni \& Torres, 2010; G. Burckhardt \& B.C. Burckhardt, 2011). This has been demonstrated in vitro by its heterologously expression following microinjection of Oat1 cRNA into Xenopus oocytes or transfection of Oat1 cDNA into epithelial cell lines (B.C. Burckhardt \& G. Burckhardt, 2003; Russel et al., 2002; Van Wert et al., 2010). Eraly et al. (2006) have generated a colony of Oat1 knockout mice, permitting the elucidation of the role of Oat1 in the context of other potentially functional redundant transporters. They found that the knockout mice manifest a profound loss of organic anion transport (e.g. PAH) both ex vivo (in isolated renal slices) as well as in vivo (as indicated by loss of renal secretion). In the case of the organic anion, furosemide, loss of renal secretion in knockout animals resulted in impaired diuretic responsiveness to this drug (Eraly et al., 2006). These results indicate an important role for Oat1 transporter in the handling of organic anions by the classical pathway.

Connected to this, we have reported an up regulation of Oat1 protein expression in rats with an early phase of acute obstructive cholestasis which might explain the increased renal elimination of the well-known organic anions, PAH and furosemide (FS) (Brandoni et al., 2006a). Performing bile duct ligation (BDL) as a well-established model of cholestasis (Brandoni \& Torres, 2009a), we have determined an increase in the systemic clearance of $\mathrm{PAH}$ associated to an increase in the abundance of Oat 1 in renal cortex homogenates in rats at $21 \mathrm{~h}$ after bile duct ligation (early phase of acute extrahepatic cholestasis) (Brandoni et al., 2003a).

FS is a well-known loop diuretic secreted through the organic anion transport system. The capacity of the organic anion transport system to secrete a diuretic determines its intraluminal concentration, which is critical for a diuretic activity. Oat1 and Oat3 are involved in the renal tubular secretion of FS and are thereby responsible for their delivery to the site of action in effective amounts (Hasannejad et al., 2004; G. Burckhardt \& B.C. Burckhardt, 2011). The protein expression of Oat1 was significantly increased both in cortical homogenates and in basolateral membranes from kidneys after 21 hours of BDL (Brandoni et al., 2006a; Brandoni et al., 2003a). This Oat1 up regulation might lead to a higher elimination of its transported compounds. In fact, we found that systemic clearance and urinary excretion of PAH were both higher in BDL rats. Connected to this, PAH uptake rate (Brandoni et al., 2006a) was increased in basolateral membranes vesicles from BDL rats showing a higher Vmax than Sham animals and no difference in Km. Moreover, Oat1 upregulation was associated with a concomitant increase of systemic and renal FS clearance.

Similar studies were performed by Brandoni et al. (Brandoni et al., 2006b) after 3 days of bile duct ligation (the peak of elevation of serum bile acids and bilirubin). After this time, BDL rats displayed a reduction in the renal elimination of PAH. Oat1 protein expression in kidney homogenates was not modified, but decreased in basolateral membranes. This study demonstrated, once more, the key role of Oat1 expression in the impaired elimination of 
PAH after 3 days of obstructive cholestasis. So, the evolution time of obstructive cholestasis has an important impact in the regulation of Oat1.

It has been described that protein kinase $\mathrm{C}(\mathrm{PKC})$ induces Oat1 down-regulation through carrier retrieval from the cell membrane. Various humoral factors induced by 3 days of bile duct ligation may probably lead to the activation of PKC. Moreover, bile acids and high bilirubin levels can activate PKC (G. Burckhardt \& B.C. Burckhardt, 2011; Hirohata et al., 2002). It has been demonstrated that 3 days of bile duct ligation is the period in which serum bile acids and bilirubin levels reach the peak of elevation. We therefore postulate that the peak of elevation of bile acids and bilirubin can also trigger PKC activation. This PKC activation may cause the phosphorylation of caveolin-2, which may induce internalization of caveolae with Oat1 protein anchored with caveolin as has been recently suggested by Kwak et. al. (2005).

In summary, in this experimental model during an early phase of acute extrahepatic cholestasis where no evident renal cell injury exists yet, an Oat1 up regulation connected with an increase in renal organic anion elimination was demonstrated. The protein expression of Oat1 was significantly increased both in cortical homogenates and in basolateral membranes from kidneys after 21 hours of BDL, which might suggest an increase in the synthesis or a decrease in the degradation of this membrane transporter. In this model, Oat1 up regulation might be found in order to enhance renal secretion of toxic compounds that may be harmful in the presence of the pathological state. Connected to this, Tanaka et al. (2002) found that bilirubin ditaurate, sulfate conjugated bile acids, and some components of the human bile up regulate the expression of Mrp2 in human renal tubular cells. On the other hand, we found an increased ${ }^{3} \mathrm{H}-\mathrm{PAH}$ uptake by $\mathrm{S} 2$ cells expressing Oat1 in the presence of bilirubin ditaurate (Brandoni et al., 2006c).

Contrary to what has been observed during an early phase of acute extrahepatic cholestasis, Oat1 expression significantly decreased in the basolateral membranes from kidneys after 3 days of bile duct ligation (Brandoni et al., 2006b). It has been suggested an internalization of membrane transporters or an inhibition in the recruitment of preformed transporters into the membranes. This study stressed, once more, the critical role of Oat1 renal expression in the excretion of $\mathrm{PAH}$, in a model of extrahepatic cholestasis in rats.

\subsection{Oat3}

Oat3 is mainly expressed in kidneys, and to a lesser extent in brain and liver. The human Oat3 gene is paired with that of Oat1 and located on chromosome 11q12.3. Inmunohistochemistry revealed the location of Oat 3 at the basolateral membrane of renal proximal tubules (Cha et al., 2001; Kojima et al., 2002). In rats, Oat3 was also found in several other nephron segments including the thick ascending limb of Henle's loop, distal convoluted tubule and collecting ducts. Oat 3 is the predominant organic anion transporter in the human kidney. Oat 3 has a broad spectrum of substrates, and it mediates the transport of PAH, ochratoxin A, estrone sulfate (ES), cimetidine, benzylpenicillin, cephaloridine and glutarate. The selectivity of Oat 3 overlaps that of Oat1, but affinities for several substrates appear to permit discrimination between both transporters. For example, Oat3 displays a moderately high affinity for ES, whereas Oat1 interacts little with ES (Sweet, 2005; Brandoni \& Torres, 2010; Torres et al., 2008; Burckhardt \& Burckhardt, 2011). Consequently, ES has 
been frequently used as a test substrate for Oat3 activity. Oat3 can operate as an organic anion/dicarboxylate exchanger (Sweet et al., 2003, Bakhiya et al., 2003). Recent experiments with tissue from Oat3 knockout mice show reduced uptake of PAH, ES, and taurocholate in renal cortical slices and nearly complete inhibition of transport of the fluorescent organic anion fluorescein in intact choroid plexus (Sweet et al., 2002).

Brandoni et al (2003a, 2006a) have studied the cortical renal expression of Oat3 in association with the pharmacokinetics and renal excretion of PAH and FS in rats with acute extrahepatic cholestasis. Male Wistar rats underwent bile duct ligation (BDL rats). All studies were carried out $21 \mathrm{~h}$ after surgery. The systemic and renal clearance of both PAH and FS increased in BDL rats. In kidneys from BDL rats, immunoblotting showed a significant increase in the abundance of both Oat1 (as described above) and Oat3 in homogenates from renal cortex. In basolateral membranes from the kidney cortex of BDL rats, Oat1 abundance was also increased and Oat3 abundance was not modified. Immunohistochemical techniques confirmed these results. Acute obstructive jaundice is associated with an upregulation of Oat1 and Oat3, which might explain, at least in part, the increased systemic and renal elimination of PAH and FS. In this connection, extrahepatic cholestasis is associated with the production of various cytokines and growth factors that may affect gene transcription (Plebani et al., 1999).

Three days of BDL is the period in which serum bile acids and bilirubin levels reach the peak of elevation (Tanaka et al., 2002; Lee et al., 2001; Pei et al., 2002). Brandoni et al (2006b) have studied Oat 1 as previously described and also Oat 3 function and expression after 3 days of BDL. After this time, BDL rats displayed a reduction in the renal elimination of PAH. Oat1 protein expression in kidney homogenates was not modified, but it decreased in the basolateral membranes. On the contrary, Oat3 expression increased both in homogenates and basolateral membranes from kidneys after three days of BDL. Oat 3 is found in various cells and in all parts of the nephron, whereas Oat1 is confined to proximal tubules (Kojima et al., 2002). The human and rat Oat3 transport PAH with relatively high affinity $(87 \mu \mathrm{mol} / \mathrm{L}$ and $65 \mu \mathrm{mol} / \mathrm{L}$ respectively) (Wright \& Dantzler, 2004; Anzai et al., 2006; Rizwan \& Burckhardt, 2007; Cha et al., 2002), similarly to Oat1. On the contrary, ES, cholate, and taurocholate are substrates for Oat3 and not for Oat1 using in vivo and in vitro methodologies (Wright \& Dantzler, 2004; Anzai et al., 2006; Rizwan \& Burckhardt, 2007; Eraly et al., 2006; Cha et al., 2002; Sweet et al., 2002). The over-expression of Oat3 does not compensate for the down-regulation of Oat1 regarding PAH transport because in this disease the high plasma levels of bile acids compete with PAH for Oat 3 transport (Brandoni et al., 2006 b; Torres, 2008). Moreover, bile acids regulate the expression of several genes involved in bile salt transport (Rost et al., 2003; Boyer et al., 2006). It is possible that high bile acid levels up-regulate Oat3 expression without affecting Oat1 expression; being this another example of substrate specific regulation.

Chen et al. (2008) have demonstrated that Oat 3 is responsible for renal secretion of bile acids during cholestasis and that the pharmacokinetic profile of Oat3 substrates may be affected by cholestasis. In obstructive cholestasis, the main route to excrete bile acids is urinary excretion. It has been demonstrated that Oat3 protein expression level is increased in Eisai hyperbilirubinemic rats (EHBR). EHBR are mutant without multidrug resistance-associated protein 2 that show higher serum and urinary concentration of bile acids, compared with Sprague-Dawley (SD) rats (wild type). On the contrary, the expression of Oat1 was 
unchanged. Moreover, the transport activities of rat and human Oat3, but not Oat1 were markedly inhibited by various bile acids such as chenodeoxycholic acid and cholic acid. Cholic acid, glycocholic acid and taurocholic acid, which mainly increased during cholestasis are transported by Oat3 (Chen et al., 2008; Burckhardt and Burckhardt, 2011). These authors also demonstrated that the plasma concentration of cefotiam, a specific substrate for Oat3, was more increased in EHBR than in SD rats despite upregulation of Oat3 : This may be due to the competitive inhibition of cefotiam transport by bile acids via Oat3. These results suggested that renal Oat3 but not Oat1 plays critical roles in the adaptative responses to the renal handling of bile acids in cholestasis.

In summary, these findings indicate that Oat3 plays an important pathophysiological role in protecting tissues from cholestatic injury by stimulating the renal secretion of bile acids. From a pharmacokinetic standpoint, it is possible that increased serum bile acids and/or administration of ursodeoxycholic acid (UDCA), recently introduced for cholestatic liver disease therapy (Paumgartner \& Beuers, 2004) could influence the tubular secretion of anionic drugs via Oat3 as was demonstrated for cefotiam. So, in this situation, more attention should be paid to prevent the occurrence of drug interaction or drug-induced toxicity.

\subsection{BTL}

The membrane protein bilitranslocase (BTL) is not a bile acid transporter, but rather a bile pigment transporter that was originally isolated from rat livers (Tiribelli et al, 1978; Passamonti et al. 2009). Bilitranslocase has been indicated as the protein responsible for the electrogenic hepatic uptake of cholephilic organic anions, such as bromosulfophtalein (BSP) and thymol blue, the tetrapyrrole bilirubin, and flavonoids (the anthocyanin malvidin 3glucoside and the flavonol quercetin) (Passamonti et al. 2009). Bilitranslocase has also been detected in basolateral plasma membranes from kidney cells and it has been demonstrated to be involved in the renal transport of BSP, bilirubin and anthocyanins (Elías et al., 1990; Vanzo et al., 2008). In this way, bilitranslocase contributes to the hepatic and renal elimination of exogenous organic anions (such as BSP), endogenous metabolites (such as bilirubin) and anthocyanins (flavonoid-based pigments that are present in many fruits and vegetables in the human diet, which have been reported to be positively implicated in human health (Vanzo et al., 2008; Passamonti et al. 2009)).

To evaluate the functional activity of bilitranslocase, we measured BSP electrogenic uptake in liver plasma membrane and in renal basolateral membrane vesicles prepared from sham and BDL rats (Brandoni et al., 2010). No modifications were observed in bilitranslocase activity and in the abundance in liver plasma membrane vesicles from BDL rats. On the contrary, extrahepatic cholestasis resulted in a marked increase of renal BSP uptake and this was due to an important increase in $\mathrm{V}_{\max }$ (capacity). The capacity of a transfer is principally determined by the total number of active carriers presented in renal basolateral membrane vesicles. The difference in $\mathrm{V}_{\max }$ indicates that a higher number of functional carrier units exists in renal basolateral membrane vesicles from BDL rats, which is in agreement with the higher expression of bilitranslocase in basolateral membranes. The observation that BDL rats have a higher renal expression of bilitranslocase at the basolateral membranes despite no change in this protein abundance in kidney homogenates suggests an alteration in bilitranslocase trafficking that might be caused by an increased recruitment of preformed 
transporters into the membranes or an inhibition in the internalization of membrane transporters.

These results suggest that the complex series of hormonal changes induced in kidneys by extrahepatic cholestasis (Sheen et al., 2010) might influence the regulation of bilitranslocase and Oatp1 in a similar way. The characteristic accumulation of bile acids, bilirubin, and other potential toxins in cholestasis may affect transcriptional and posttranscriptional regulatory mechanisms (Donner et al., 2007; Geier et al., 2007). In this connection, as it has been mentioned earlier, bilirubin, sulfate-conjugated bile acid and human bile up regulated the expression of Mrp2 in renal tubular cells but not in liver cells (Tanaka et al., 2002).

In summary, the higher renal expression and function of bilitranslocase in renal basolateral membranes from rats with obstructive cholestasis might also contribute to the dramatic increase in BSP renal excretion observed in this experimental model. This would be another compensation mechanism to overcome the hepatic dysfunction in the elimination of organic anions.

\subsection{BBBP}

$\mathrm{BSP} /$ Bilirubin binding protein (BBBP) is a protein isolated from rat liver located on the sinusoidal membrane of the liver and described as a transport protein involved in the well known sodium-independent hepatic uptake of BSP and bilirubin (Stremmel \& Berk, 1986; Stremmel et al., 1986; Torres et al., 1993; Torres, 1997). The transport of this protein is electroneutral as indicated by experiments in liver plasma membrane vesicles. BBBP is an organic anion carrier protein expressed in both apical and basolateral membranes from rat kidney cells, which accounts at least in part, for the renal tubular transport of PAH (Torres et al. 2003).

Brandoni et al. (2003b; 2004a; 2004b) have described an increment in BBBP expression in homogenates and in basolateral membranes from kidney cortex after $21 \mathrm{~h}$ of obstructive cholestasis without modifications in its apical membrane expression. The increase in BBBP homogenate expression suggests an increment in its synthesis or a decrease in its degradation, while the traffic protein is preferably directed to the basolateral domain. The higher basolateral membrane expression of BBBP could contribute to the higher BSP and PAH renal excretion described in this experimental model of acute cholestasis (Brandoni et al., 2003b; Brandoni et al., 2004a; Brandoni et al., 2004b).

In summary, modifications in hepatic excretion of organic anions have been demonstrated in rats with extrahepatic cholestasis. We have evaluated, in rats with acute bile duct ligation, the urinary excretion of two different organic anions, PAH mainly excreted by the kidneys and BSP mainly excreted by the liver.

The higher abundance of the organic anions carrier BBBP, detected in rats with obstructive jaundice might explain, at least in part, the higher renal capacity to eliminate distinct negatively charge compounds in this group of rats. These results suggest a relevant role of this kind of transporters in renal elimination of those organic anions excreted mainly by liver, in the presence of the obstructive cholestasis. 


\subsection{ASBT}

The sodium dependent bile salt transporter (ASBT) is expressed in the ileum, the apical membrane of cholangiocytes and in the brush border membrane of proximal tubular cells (Christie et al., 1996; Lazaridis et al., 1997; Wilson et al. 1981; Burckhardt et al. 1987).

Bile acids, after secretion with the bile into the small intestine, are nearly completely reabsorbed in the terminal ileum. They return with the portal venous blood to the liver where they are taken up and resecreted into the bile. Some $10-50 \%$ of the reabsorbed bile acids (depending on the bile acid species) escape hepatic uptake and spill over in the peripheral circulation. About $10-30 \%$ of the bile acids, presents in the blood plasma, is not protein-bound and hence is subject to glomerular filtration (Rudman \& Kendall, 1957). However, urinary excretion of bile acids is much smaller than the amount filtered due to a nearly complete tubular reabsorption of the filtered bile acids (Weiner et al., 1964; Barnes et al. 1977). Thus, the kidneys also take part in the recirculation process and aid to conserve bile acids. Tubular reabsorption of bile acids is accomplished by ASBT (Wilson et al. 1981; Burckhardt et al. 1987).

After a 14 day bile duct obstruction, a decreased taurocholate transport of brush border membrane vesicles derived from rat kidneys has been found by Lee et al. (2001). The reduced taurocholate uptake was associated with a reduction of renal ABST protein expression in membrane-rich microsomal fractions prepared from rat kidneys.

Schlattjan et al. (2003) have demonstrated that as early as 1 day after induction of an obstructive cholestasis a reduced taurocholate transport of proximal tubular cells can occur without a change in the amount of the transport protein in these cells. The diminished taurocholate transport in this early phase of cholestasis may be mediated by a change of the phosphorylation status and hence activity of ASBT and/or by a redistribution of the transporter between the plasma membrane and intracellular compartments of the proximal tubular cells.

In summary, these studies have demonstrated that there is a functional adaptive down regulation of renal tubular bile acid transport enhancing renal clearance of bile acids during the early phase of an obstructive cholestasis.

\subsection{Oatp1}

Organic anion-transporting polypeptides (Oatp) are a group of membrane solute carriers with a wide spectrum of amphipathic transport substrates. Several members of the Oatp family are located in the apical membrane of proximal tubules, and have been suggested to play a role in the secretion/reabsorption of selected anionic substrates (Hagenbuch \& Meier, 2003; Kalliokoski \& Niemi, 2009; Hagenbuch 2010).

The first member of the Oatp gene family of membrane transporters, Oatp1, has been isolated from rat liver and shown to mediate $\mathrm{Na}^{+}$-independent saturable transport of BSP (Hagenbuch \& Meier, 2003). Oatp1 is also localized, in addition to the basolateral plasma membrane of hepatocytes, at the apical membranes of kidney proximal tubule (S3 segment). Thus, this transporter could be responsible for reabsorption of organic compounds that are freely filtered, such as estradiol-17 $\beta$-glucuronide, or important for the secretion of certain organic compounds that are taken up into proximal tubular cells across the basolateral 
membrane (Gotoh et al., 2002; Obadait et al., 2012). However, it is surprising that BSP, a known substrate for the Oatp1 transport, is normally secreted negligibly by the kidney in non-pathological conditions.

Regulation of Oatp1 expression and function occurs at transcriptional and posttranscriptional levels and is, at least in part, tissue-specific. Thus, while in the kidney Oatp1 expression is stimulated by testosterone and inhibited by estrogens, hepatic Oatp1 expression is not influenced by sex hormones (Gotoh et al., 2002; Wood et al., 2005; Rost et al., 2005). Functional down regulation of Oatp1 has been demonstrated via serine phosphorylation by extracellular ATP (Hagenbuch \& Meier, 2004). In addition, protein kinase $\mathrm{C}$ activation leads to decreased transport of estrone-3-sulfate in Oatp1 expressing X. laevis oocytes (Geier et al., 2007; Planchamp et al, 2007).

In rats with cholestasis due to bile duct ligation, the hepatic expression of Oatp1 is down regulated (Geier et al., 2007). This transporter mediates hepatic uptake of numerous organic anions from the systemic circulation. This observation may also be an adaptive change because BDL rats need to restrict excess uptake of various organic anions into hepatocytes. Renal Oatp1 mediates urinary excretion and re-uptake of organic anions at apical (brush border) membrane. It is worth noting that differential processing and trafficking of this transporter in liver and kidney may have important functional and regulatory consequences.

Our data showed that BDL rats have a higher renal expression of Oatp1 protein at apical membranes despite no change in Oatp1 abundance in kidney homogenates (Brandoni et al., $2009 \mathrm{~b}$ ). These observations suggest an alteration in Oatp1 trafficking that might be caused by an increased recruitment of preformed transporters into the membranes or an inhibition in the internalization of membrane transporters. The results of this study have shown that the kidneys are able to adapt rapidly to obstructive cholestasis because BSP renal elimination had increased nearly 30-fold during the first day after induction of bile duct obstruction. This study has shown evidence that this renal adaptation to cholestasis involves an up regulation of the transport capacity of the proximal tubular organic aniontransporting polypeptide 1, Oatp1. This increase in Oatp1 protein units at the apical membrane of renal cells may be a compensatory mechanism for reducing injury to hepatocytes or renal epithelia from cytotoxic materials that may occur in rats with obstructive cholestasis.

Extrahepatic cholestasis induces a complex series of hormonal changes in kidneys (Sheen et al., 2010), which might influence the regulation of Oatp1. Likely several local and systemic factors are produced at the same time, and the role of such factors in the regulation of channels and transporters, in renal cells, in the presence of BDL is still unknown. Probably, the accumulation of bilirubin, bile acids and other potential toxics existing in this cholestatic model may affect transcriptional regulatory mechanisms (e.g. fetal transcription factor, pregnene $X$ receptor) and post-transcriptional regulations (Cheng et al., 2005).

In summary, we present evidence that cholestasis induced by common BDL in the rat induces a redistribution in renal Oatp1 protein units into apical membranes from renal cells (Brandoni et al., 2009b). Moreover, this likely adaptation to hepatic injury, specifically in biliary components elimination, present in this model might explain, at least in part, the huge increase in BSP renal excretion observed in this experimental model. 


\subsection{Mrp2}

This transporter is a primary-active ATP-dependent pump, identified as multidrug resistance-associated protein 2 (Mrp2) (Klaassen \& Aleksunes, 2010; Keppler, 2011). As in hepatocytes, renal proximal tubular cells and jejunal cells also exhibit constitutive expression of Mrp2 at the apical membrane (Schaub et al., 1997).

Mrp2 is involved in the organic anion transport of a wide variety of potentially toxic endoand xenobiotics incluiding bilirubin, drugs, and carcinogens, e.g. in the form of amphiphilic anionic conjugates. In addition, Mrp2 mediates the transport of BSP-conjugated derivates (Nies \& Keppler, 2007; Passamonti et al. 2009). It has also been described that Mrp2 mediates PAH transport in kidneys (Van Aubel et al., 2000; Leier et al., 2000).

In obstructive jaundice, adaptive mechanisms may permit the liver adapts to the higher load of biliary constituents in part by altering the expression of hepatobiliary transporters. In fact, studies of the regulation of the canalicular Mrp2 transporter have described reduced levels of mRNA and protein in rats after bile duct ligation (Denson et al., 2002; Dietrich et al., 2004).

Scarce data is available reporting the role of extrahepatic tissues in Mrp2 substrate disposition under conditions of deficient biliary secretory function. Lee et al. (2001) have reported that the up regulation in Mrp2 protein in kidney occurred as early as one day after BDL. On the other hand, Tanaka et al. (2002) have evaluated renal Mrp2 function by PAH clearance in rats with obstructive jaundice. PAH clearance was significantly increased after BDL. They also found an increased in mRNA and protein expression of Mrp2 in BDL animals. In this work, the effect of conjugated bilirubin, unconjugated bilirubin, human bile, and sulfate-conjugated bile acid on Mrp2 gene expression was also evaluated in human renal proximal tubular epithelial cells. They have described that the mRNA expression of Mrp2 increased in these renal cells after treatment with conjugated bilirubin, sulfateconjugated bile acid or human bile. These results suggest that increased renal Mrp2 is functionally active during obstructive jaundice and the increased Mrp2 expression in the kidneys may provide an alternative pathway for accelerating excretion of bilirubin conjugates during obstructive jaundice.

It has been demonstrated a minor role of the intestine in compensating for altered liver Mrp2 mediated secretory function. In fact, Dietrich et al. (2004) have indicated that the expression of Mrp2 in the intestine was down regulated in rats with obstructive cholestasis. A role for increased levels of interleukin-1 $\beta$ was implicated in down-regulation of Mrp2 in both liver and intestine from rats undergoing extrahepatic cholestasis. It was demonstrated that decreased binding of RARa:RXRa nuclear receptor dimer to the promoter region of Mrp2 in BDL rats, due to increased levels of interleukin-1 $\beta$, accounts for Mrp2 downregulation in liver. In contrast, renal cortex exhibits up-regulation of expression and function of Mrp2 in BDL rats, which likely results from preserved levels of RARa:RXRa dimer in this tissue. Additionally, it was shown increased renal tubular conversion of 1chloro-2,4-dinitrobenzene (CDNB) to its glutathione conjugate dinitrophenyl-S-glutathione (DNP-SG) followed by subsequent Mrp2-mediated secretion into urine that partially compensates for altered liver function in experimental obstructive cholestasis (Villanueva et al., 2006). It is worth noting that these results might also explain the increase in BSP and PAH excreted load seen in BDL rats (Brandoni \& Torres, 2009; Brandoni et al., 2010; Brandoni et al., 2003a). 
In summary, these results confirm that the up regulation of the apical transporter Mrp2 in kidneys is involved in the higher secretion into urine of organic anions, such as BSP, PAH and DNP-SG. The current data demonstrate the relevance of the renal elimination, particularly under conditions of impaired biliary secretory function, as occurs in obstructive cholestasis that partially compensates for altered liver function in this pathology.

\section{Conclusions}

The higher expression of Oat1 and BBBP at the basolateral domain of renal tubular cells together with the increased expression of Mrp2 at apical membrane could justify the increased excretion of PAH and FS described after $21 \mathrm{~h}$ of obstructive jaundice (Brandoni et al., 2003a; Brandoni et al., 2006; Brandoni et al., 2003b; Brandoni et al., 2004a; Brandoni et al., 2004b; Tanaka et al., 2002; Villanueva et al., 2006).

As it has been already mentioned, BSP is an organic anion mainly excreted by the liver, which is a substrate for several carrier proteins such as Oat3, Oatp1, Mrp2 and bilitranslocase. We have demonstrated an increase in BSP urinary excretion in rats with extrahepatic cholestasis associated with a higher expression of Oatp1 in apical membranes and an unchanged expression of Oat 3 in basolateral membranes from kidneys (Brandoni et al, 2003a; Brandoni et al., 2006; Brandoni \& Torres, 2009b). Moreover, Mrp2 up regulation in kidneys from BDL rats has been described (Tanaka et al., 2002; Villanueva et al., 2006).

The increase in Oat1, bilitranslocase and BBBP protein units at renal basolateral membrane together with the increased expression of Oatp1 and Mrp2, and the fall in ABST function, at the apical domain of renal cells may be a compensatory mechanism for protecting hepatocytes or kidney cells from cytotoxic substances that accumulate in the presence of obstructive cholestasis. The upregulation observed in BTL, BBBP, Oatp1 and Mrp2 might explain the dramatic increase in BSP renal elimination displayed in this pathology (Brandoni et al., 2009b; Brandoni et al., 2010).

On the other hand, it has also been found that urinary excretion of bile acids is markedly increased in obstructive liver diseases (Ostrow, 1993). The increase in bile acids urinary excretion may be a consequence of the fact that the amount of filtered bile acids in cholestasis exceeds the maximum capacity for tubular reabsorption. But it may also involve adaptive mechanisms of the kidneys, such as a decline of tubular apical reabsorption of bile acids and an enhanced tubular basolateral uptake.

Mrp2 and the sodium-dependent bile salt transporter ABST are two renal apical bile acids carriers; Mrp2 mediates the exit of bile acids from the cells and ABST is involved in their reabsorption. As was previously mentioned, Mrp2 is upregulated (Tanaka et al., 2002) and there is a fall in the function of ABST (Schlattjan et al., 2003) in the presence of acute extrahepatic cholestasis. Both mechanisms may also contribute to the increased excretion of bile acids in the presence of this pathology. On behalf of the basolateral domain, Oat3 transports bile acids from the blood into the cells. As it has been mentioned earlier, its expression at the basolateral membrane does not change in this experimental model of $21 \mathrm{~h}$ of acute extrahepatic cholestasis in rats (Brandoni et al., 2006a).

Figure 2 shows a summary of expression modifications in organic anion transporters detected after acute extrahepatic cholestasis and table 1 shows their consequences in urinary excretions of BSP, PAH and FS. 


\section{Organic anions renal secretion}

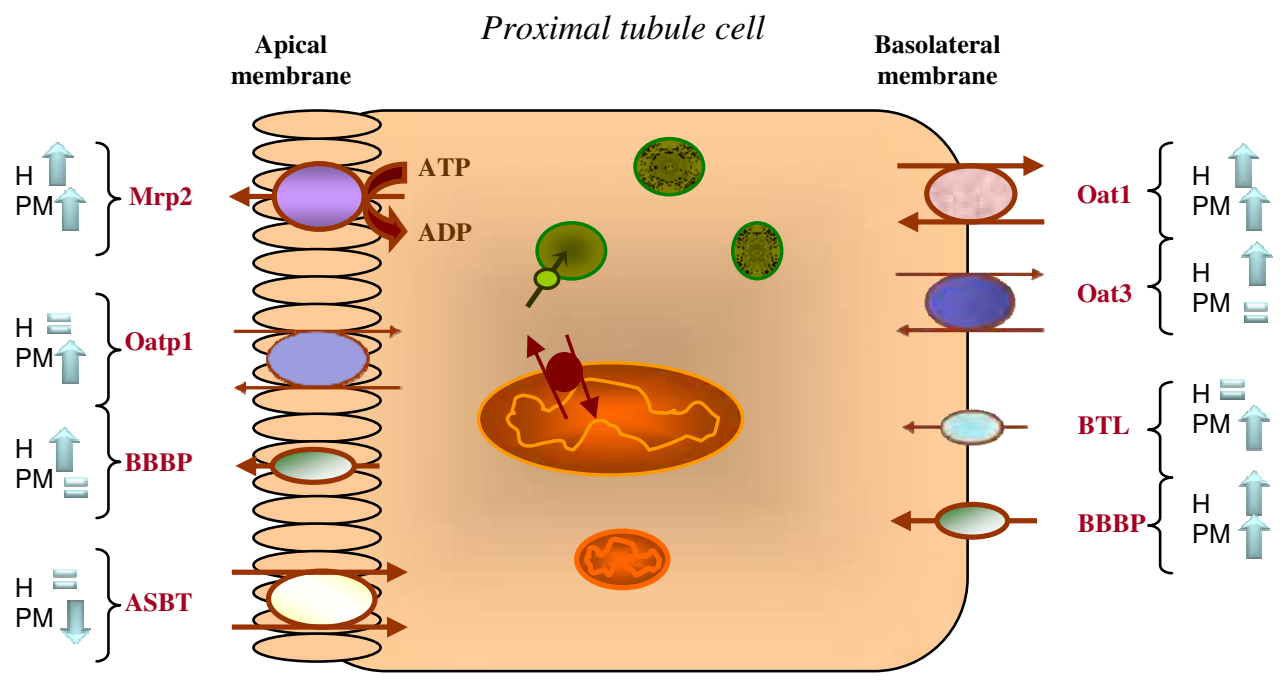

Fig. 2. Expression of the organic anion transporters in proximal renal tubule cell during extrahepatic cholestasis in the rat. For proteins abbreviations see the text. H: homogenate; PM: plasma membrane.

\begin{tabular}{|c|c|c|c|c|}
\hline & & \multicolumn{3}{|c|}{ Renal excreted loads } \\
\hline \multicolumn{2}{|c|}{ Protein abundance } & PAH & FS & BSP \\
\hline \multicolumn{5}{|l|}{ Oat1 } \\
\hline BTL & 1 & & & \\
\hline \multicolumn{5}{|l|}{ BBBPa } \\
\hline Oatp1 & 1 & & & \\
\hline Mrp2 & 1 & & & \\
\hline
\end{tabular}

(a)Apical expression of BBBP was not changed compared to sham animals while basolateral expression was increased as indicated in the table.

Table 1. Renal organic anions transporters: basolateral and apical membrane proteins in proximal tubule cell. The table summarizes our results about the renal excretion of the organic anions, PAH, FS and BSP and their relationship with renal expression of the organic anion transporters studied in rats after $21 \mathrm{~h}$ of BDL. 
To sum up, as a consequence of the hepatic function impairment, alterations in the renal elimination of organic anions were observed. The higher abundances of the organic anions carriers detected in rats with extrahepatic cholestasis might explain the higher renal capacity to eliminate distinct negatively charge compounds in this group of rats. These results suggest a relevant role of these transporters in renal elimination of those organic anions excreted mainly by liver, in the presence of the obstructive cholestasis.

The knowledge of how these transporters are regulated in the presence of pathological states, such as extrahepatic cholestasis, will help to design optimal therapeutics regimens for the most correct use of negatively charged organic drugs.

\section{Acknowledgment}

This study was supported by grants from: Fondo para la Investigación Científica y Tecnológica (FONCYT), Consejo Nacional de Investigaciones Científicas y Técnicas (CONICET), Universidad Nacional de Rosario (UNR). The authors thank to Prof. H. Endou and to Dr N. Anzai (Department of Pharmacology and Toxicology, Kyorin University School of Medicine, Tokyo, Japan) for kindly providing Oat1 and Oat3 specific antibodies, to Prof. S. Passamonti (Department of Life Science, Trieste University, Italy) for kindly providing BTL specific antibodies and to Prof. W. Stremmel (Medizinische Universitatsklinik, Heidelberg University, Germany) for kindly providing BBBP specific antibodies.

\section{References}

Anzai, N.; Kanai, Y. \& Endou, H. (2006). Organic anion transporter family: current knowledge. J. Pharmacol. Sci. Vol.100, 411-426.

Bakhiya, A.; Bahn, A.; Burckhardt, G. \& Wolff, N. (2003). Human organic anion transporter 3 (hOAT3) can operate as an exchanger and mediate secretory urate flux. Cell. Physiol. Biochem. Vol.13, 249-256.

Barnes, S.; Gollan, J.L. \& Billing B.H. (1977). The role of tubular reabsorption in the renal excretion of bile acids. Biochem. J. Vol.166, 65-73.

Boyer, J.L.; Trauner, M.; Mennone, A.; Soroka, C.J.; Cai, S.Y.; Moustafa, T.; Zollner, G.; Lee, J.Y \& Ballatori, N. (2006). Upregulation of a basolateral FXR-dependent bile acid efflux transporter OSTalpha-OSTbeta in cholestasis in humans and rodents. Am J Physiol Gastrointest 290: G1124-G1130 .

Brandoni, A.; Quaglia, N.B. \& Torres, A.M. (2003a). Compensation increase in organic anion excretion in rats with acute biliary. Pharmacology Vol.68, 57-63.

Brandoni, A.; Villar, S.R.; Stremmel, W. \& Torres, A.M. (2003b). Proteínas transportadoras involucradas en la eliminación renal de bromosulfoftaleína en ratas con colestasis extrahepática. Medicina Vol.63, No.5, 189 (Abstract).

Brandoni, A.; Villar, S.R.; Quaglia, N.B. \& Torres, A.M. (2004a). Improvement in renal excretion of different organic anions in rats with extrahepatic cholestasis. Liver International Vol.24, No.4, P-63 (Abstract).

Brandoni, A.; Villar, S.R.; Quaglia, N.B. \& Torres, A.M. (2004b). Elimination of paminohippurate (PAH) and sulfobromophthalein (BSP) in rats with extrahepatic 
cholestasis (EHC) of 21 hours. A comparative study. Biocell Vol.28, No.2, 64 (Abstract).

Brandoni, A.; Villar, S.R.; Picena, J.C.; Anzai, N.; Endou, H. \& Torres, A.M. (2006a). Expression of rat renal cortical OAT1 and OAT3 in response to acute biliary obstruction. Hepatology Vol.43, 1092-1100.

Brandoni, A.; Anzai, N.; Kanai, Y.; Endou, H. \& Torres, A.M. (2006b). Renal elimination of paminohippurate (PAH) in response to three days of biliary obstruction in the rat. The role of OAT1 and OAT3. Biochim. Biophys. Acta Vol.1762, 673-682.

Brandoni, A.; Villar, S. R.; Anzai, N.; Endou, H. \& Torres, A. M. (2006c). Modifications in paminohippurate renal transport in rats with acute biliary obstruction. Physiol. Minireviews Vol.2, 181 (Abstract).

Brandoni, A. \& Torres, A.M. (2009a). Extrahepatic cholestasis model, In: Experimental Surgical Models in the Laboratory Rat, A. Rigalli, V. Di Loreto (eds), pp 139-141, CRC Press Taylor and Francis Group, Boca Ratón, USA.

Brandoni, A. \& Torres, A.M. (2009b). Characterization of the mechanisms involved in the increased renal elimination of bromosulfophthalein during cholestasis: involvement of Oatp1. J. Histochem. Cytochem. Vol.57, 449-456.

Brandoni, A. \& Torres, A.M. (2010). Expression and function of renal organic anion transporters (Oats) in health and disease. Current Topics in Pharmacology 14: 1-9.

Brandoni, A.; Di Giusto, G.; Franca, R.; Passamonti, S. \& Torres, A.M. (2010) Expression of kidney and liver bilitranslocase in response to acute biliary obstruction. Nephron Physiol. Vol.114, 35-40.

Burckhardt, G.; Kramer, W.; Kurz, G. \& Wilson, F.A. (1987). Photoaffinity labeling studies of the rat renal sodium bile salt cotransport system. Biochem. Biophys. Res. Commun. Vol.143, 1018-1023.

Burckhardt G. \& Pritchard J.B. (2000). Organic anion and cation antiporters, In: The Kidney. Physiology and Pathophysiology. Third edition. D.W. Seldin \& G. Giebisch (eds), pp 193-222, LIPPINCOTT WILLIAMS \& WILKINS, Philadelphia, USA.

Burckhardt, B.C. \& Burckhardt, G. (2003). Transport of organic anions across the basolateral membrane of proximal tubule cells. Rev. Physiol. Biochem. Pharmacol. Vol.146, 95158.

Burckhardt, G. \& Burckhardt, B.C. (2011). In vitro and in vivo evidence of the importance of organic anion transporters (OATs) in drug therapy, In: Drug transporters, Handbook of experimental pharmacology 201. M.F. Fromm \& R.B. Kim (eds), pp 29-104, SpringerVerlag, Berlin, Germany.

Cha, S.H.; Sekine, T.; Fukushima, J.I.; Kanai, Y.; Kobayashi, Y.; Goya, T. \& Endou, H. (2001). Identification and characterization of human organic anion transporter 3 expressing predominantly in the kidney. Mol. Pharmacol. Vol.59, 1277-1286.

Chen, J.; Terada, T.; Ogasawara, K.; Katsura, T. \& Inui, K-I. (2008). Adaptive responses of renal organic anion transporter 3 (OAT3) during cholestasis. Am. J. Physiol. Vol.295, F247-F252.

Cheng, X.; Maher, J.; Dieter, M.Z. \& Klaassen, C.D. (2005) Regulation of mouse organic anion-transporting polypeptides (oatps) in liver by prototypical microsomal enzyme inducers that activate distinct transcription factor pathways. Drug Metab. Dispos. Vol.33, 1276-1282. 
Christie, D.M.; Dawson, P.A.; Thevananther, S. \& Schneider, B.L. (1996). Comparative analysis of the ontogeny of a sodium-dependent bile acid transporter in rat kidney and ileum. Am. J. Physiol. Vol.271, G377-G385.

Denk, G.U.; Soroka, C.J.; Takeyama, Y.; Chen, W.S.; Schuetz, J.D. \& Boyer, J.L. (2004). Multidrug resistance-associated protein 4 is up-regulated in liver but downregulated in kidney in obstructive cholestasis in the rat. J. Hepatol. Vol.40, 585-591.

Denson, L.A.; Bohan, A.; Held, M.A. \& Boyer, J.L. (2002). Organ-specific alterations in RAR alpha:RXR alpha abundance regulate rat Mrp2 (Abcc2) expression in obstructive cholestasis. Gastroenterology Vol.123, 599-607.

Dietrich, C.; Geier, A.; Salein, N.; Lammert, F.; Roeb, E.; Oude Elferink, R.P.; Matern, S. \& Gartung, C. (2004). Consequences of bile duct obstruction on intestinal expression and function of multidrug resistance-associated protein 2. Gastroenterology Vol.126, 1044-1053.

Donner, M.G.; Schumacher, S.; Warskulat, U.; Heinemann, J. \& Häussinger, D. (2007). Obstructive cholestasis induces TNF-a- and IL-1b-mediated periportal downregulation of Bsep and zonal regulation of Ntcp, Oatp1a4, and Oatp1b2. Am. J. Physiol. Vol.293, G1134-G1146.

Elías, M.M.; Lunazzi, G.C.; Passamonti, S.; Gazzin, B.; Miccio, M.; Stanta, G.; Sottocasa, G.L. \& Tiribelli, C. (1990). Bilitranslocase localization and function in basolateral plasma membrane of renal proximal tubule in rat. Am. J. Physiol. Vol.259, F559-F564.

El-Sheikh, A.A.K.; Masereeuw, R. \& Russel, F.G.M. (2008). Mechanisms of renal anionic druf transport. Eur. J. Pharmacol. Vol.585, 245-255.

Eraly, S.A.; Vallon, V.; Vaughn, D.A.; Gangoiti, J.A.; Richter, K.; Nagle, M.; Monte, J.C.; Rieg, T.; Truong, D.M.; Long, J.M.; Barshop, B.A.; Kaler, G. \& Nigam, S.K. (2006). Decreased renal organic anion secretion and plasma accumulation of endogenous organic anions in OAT1 knock-out mice. J. Biol. Chem. Vol. 281, 5072-5083.

Geier, A.; Dietrich, C.G.; Trauner, M. \& Gartung, C. (2007). Extrahepatic cholestasis downregulates Oatp1 by TNF-alpha signalling without affecting Oatp2 and Oatp4 expression and sodium-independent bile salt uptake in rat liver. Liver Int. Vol.27, 1056-1065.

Gotoh, Y.; Kato, Y.; Stieger, B.; Meier, P.J. \& Sugiyama Y (2002). Gender difference in the Oatp1-mediated tubular reabsorption of estradiol 17beta-D-glucuronide in rats. Am. J. Physiol. Vol.282, E1245-1254.

Hasannejad H., Takeda M., Taki K., Shin H.J., Babu E., Jutabha P., Khamdang S., Aleboyeh M., Onozato M.L., Tojo A., Enomoto A., Anzai N., Narikawa S., Huang X., Niwa T. \& Endou H. (2004). Interactions of human organic anion transporters with diuretics. J. Pharmacol. Exp. Ther. Vol.308, 1021-1029.

Hirohata, Y.; Fujii, M.; Okabayashi, Y.; Nagashio, Y.; Tashiro, M.; Imoto, I.; Akiyama, T. \& Otsuki, M. (2002). Stimulatory effects of bilirubin on amylase release from isolated rat pancreatic acini. Am. J. Physiol. Vol.282, 242-256.

Hagenbuch, B. \& Meier, P.J. (2003). The superfamily of organic anion transporting polypeptides. Biochim. Biophys. Acta Vol.1609, 1-18.

Hagenbuch, B. \& Meier, P.J. (2004). Organic anion transporting polypeptides of the OATP/SLC21 family: phylogenetic classification as OATP/ SLCO superfamily, new nomenclature and molecular/functional properties. Pflügers Arch. Vol.447, 653-65. 
Hagenbuch, B. (2010). Drug uptake systems in liver and kidney: a historic perspective. Clin. Pharmacol. Ther. 87:39-47.

Kalliokoski, A. \& Niemi, M. (2009). Impact of OATP transporters on pharmacokinetics. Br. J. Pharmacol. Vol.158, 693-705.

Keppler, D. (2011). Multidrug resistance proteins (MRPs, ABCCs): importance for pathophysiology therapy, In: Drug transporters, Handbook of experimental pharmacology 201. M.F. Fromm \& R.B. Kim (eds), pp 299-323, Springer-Verlag, Berlin, Germany.

Klaassen, C.D. \& Aleksunes, L.M. (2010). Xenobiotic, bile acid, and cholesterol transporters: function and regulation. Pharmacol. Rev. Vol.62, 1-96.

Kojima, R.; Sekine, T.; Kawachi, M.; Cha, S.H.; Suzuki, Y. \& Endou, H. (2002). Immunolocalization of multispecific organic anion transporters, OAT1, OAT2, and OAT3, in rat kidney. J. Am. Soc. Nephrol. Vol.13, 848-857.

Kwak, J.O. ; Kim, H-W. ; Oh, K-J. ; Kim, D.S. ; Han, K.O. \& Cha, S.H. (2005). Colocalization and interaction of organic anion transporter 1 with caveolin-2 in the kidney. Exp. Mol. Med. Vol.37, 204-212.

Lazaridis, K.N.; Pham, L.; Tietz, P., Marinelli, R.A.; deGroen, P.C.; Levine, S.; Dawson, P.A. \& LaRusso, N.F. (1997). Rat cholangiocytes absorb bile acids at their apical domain via the ileal sodium-dependent bile acid transporter. J. Clin. Invest. Vol.100, 27142721.

Lee, J.; Azzaroli, F.; Wang, L., Soroka, C.J.; Gigliozzi, A.; Setchell, K.D.; Kramer, W. \& Boyer, J.L. (2001). Adaptive regulation of bile salt transporters in kidney and liver in obstructive cholestasis in the rat. Gastroenterology Vol.121, 1473-1484.

Leier, I.; Hummel-Eisenbeiss, J.; Cui, Y. \& Keppler, D. (2000). ATP-dependent paraaminohippurate transport by apical multidrug resistance protein MRP2. Kidney Int. Vol.57, 1636-1642.

Nies, A.T. \& Keppler, D. (2007). The apical conjugate efflux pump ABCC2 (MRP2). Pflügers Arch Vol.453, 643 - 659.

Obaidat, A.; Roth, M. \& Hagenbuch, B. (2012). The expression and function of organic anion transporting polypeptides in normal tissues and in cancer. Annu. Rev. Pharmacol. Toxicol. Vol.52, 135-51.

Ostrow, J.D. (1993). Metabolism of bile salts in cholestasis in humans, In: Hepatic Transport and Bile Secretion: Physiology and Pathophysiology, N. Tavolin, P.D. Berk (eds), pp 673-712, Raven Press, New York, USA.

Planchamp, C.; Hadengue, A.; Stieger, B.; Bourquin, J.; Vonlaufen, A.; Frossard, J-L.; Quadri, R.; Becker, C.D. \& Pastor, C.M. (2007). Function of Both Sinusoidal and Canalicular Transporters Controls the Concentration of Organic Anions within Hepatocytes. Mol. Pharmacol. Vol.71, 1089-1097.

Passamonti, S.; Terdoslavich, M.; Franca, R.; Vanzo, A.; Tramer, F.; Braidot, E.; Petrussa, E. \& Vianello, A. (2009). Bioavailability of flavonoids: a review of their membrane transport and the function of bilitranslocase in animal and plant organisms. Curr. Drug Metab. Vol.10, 369-394.

Paumgartner, G.\& Beuers, U. (2004). Mechanisms of action and therapeutic efficacy of ursodeoxycholic acid in cholestatic liver disease. Clin. Liver Dis. Vol.8, 67-81.

Pei, Q.L.; Kobayashi, Y.; Tanaka, Y.; Taguchi, Y.; Higuchi, K.; Kaito, M.; Ma. N.; Semba, R.; Kamisako, T. \& Adachi, Y. (2002). Increased expression of multidrug resistance- 
associated protein 1 (mrp1) in hepatocyte basolateral membrane and renal tubular epithelia after bile duct ligation in rats. Hepatol. Res. Vol.22, 58-64

Plebani, M.; Panozzo, M.P.; Basso, D.; De Paoli, M.; Biasin, R. \& Infantolino, D. (1999). Cytokines and the progression of liver damage in experimental bile duct ligation. Clin. Exp. Pharmacol. Physiol. Vol. 26, 358-363.

Reichen, J. \& Simon, F.R. (1988). Cholestasis, In: The Liver: Biology and Pathobiology. Second Edition, I.M. Arias, W.B. Jakoby, H. Popper, D. Schachter \& D.A. Shafritz (eds), pp 1105-1124, Raven Press Ltd., New York, USA.

Rizwan, A.N. \& Burckhardt, G. (2007). Organic anion transporters of the SLC22 family: biopharmaceutical, physiological, and pathological roles. Pharm. Res. Vol.24, 450470.

Rost, D.; Herrmann, T.; Sauer, P.; Schmidts, H.L.; Stieger, B.; Meier, P.J.; Stremmel, W. \& Stiehl, A. (2003). Regulation of rat organic anion transporters in bile salt-induced cholestatic hepatitis: effect of ursodeoxycholate. Hepatology; 38: 187-195.

Rost, D.; Kopplow, K.; Gehrke, S.; Mueller, S.; Friess, H.; Ittrich, C.; Mayer, D. \& Stiehl, A. (2005). Gender-specific expression of liver organic anion transporters in rat. Eur. J. Clin. Invest. Vol.35, 635-643.

Rudman, D. \& Kendall, F.E. (1957). Bile acid content of human serum. II. The binding of cholanic acid by human plasma proteins. J. Clin. Invest. Vol.36, 538-542.

Russel, F.G.M.; Masereeuw, R. \& van Aubel, R.A.M.H. (2002). Molecular aspects of renal anionic drug transport. Annu. Rev. Physiol. Vol.64, 563-594.

Schaub, T.P.; Kartenbeck, J.; König, J.; Vogel, O.; Witzgall, R.; Kritz, W. \& Keppler, D (1997). Expression of the conjugate export pump encoded by the mrp2 gene in the apical membrane of kidney proximal tubules. J. Am. Soc. Nephrol. Vol.8, 1213-1221.

Schlattjan, J.H.; Winter, C. \& Greven, J. (2003) Regulation of renal tubular bile acid transport in the early phase of an obstructive cholestasis in the rat. Nephron Physiol. Vol.95, $49-56$.

Sheen, J-M. , Huang, L-T.; Hsieh, C-S.; Chen, C-C.; Wang, J-Y. \& Tain, Y-L. (2010). Bile duct ligation in developing rats: temporal progression of liver, kidney, and brain damage. J. Pediatr. Surg. Vol.45, 1650-1658.

Slitt, A.L.; Allen, K.; Morrone, J.; Aleksunes, L.M.; Chen, C.; Maher, J.M.; Manautou, J.E.; Cherrington, N.J. \& Klaassen, C.D. (2007). Regulation of transporter expression in mouse liver, kidney, and intestine during extrahepatic cholestasis. Biochim. Biophys. Acta Vol.1768, 637-647.

Stremmel, W.; Gerber, M.A.; Glezerov, V.; Thung, S.N.; Kochwa, S. \& Berk, P. (1983). Physicochemical and immunohistochemical studies of a sulfobromophthalein and bilirubin-binding protein from rat liver plasma membrane. J. Clin. Invest. Vol.71, 1796-1805.

Stremmel, W. \& Berk, P. (1986). Hepatocellular uptake of sulfobromophthalein and bilirubin is selectively inhibited by an antibody to the liver plasma membrane sulfobromophthalein/ bilirubin binding protein. J. Clin. Invest. Vol.78, 822-826.

Sweet, D.H.; Miller, D.S.; Pritchard, J.B.; Fujiwara, Y.; Beier, D.R. \& Nigam, S.K. (2002). Impaired organic anion transport in kidney and choroid plexus of organic anion transporter 3 (Oat3 (Slc22a8)) knockout mice. J. Biol. Chem. Vol.277, 26934-26943.

Sweet, D.H.; Chan, L.M.; Walden, R.; Yang, X.P.; Miller, D.S. \& Pritchard, J.B. (2003). Organic anion transporter 3 (Slc22a8) is a dicarboxylate exchanger indirectly coupled to the Na+ gradient. Am. J. Physiol. Vol.284, F763-F769. 
Sweet, D.H. (2005). Organic anion transporter (Slc22a) family members as mediators of toxicity. Toxicol. Appl. Pharmacol. Vol.204, 198-215.

Tanaka, Y.; Kobayashi, Y.; Gabazza, E.C.; Higuchi, K.; Kamisako, T.; Kuroda, M.; Takeuchi, K.; Iwasa, M.;, Kaito, M. \& Adachi Y. (2002)Increased renal expression of bilirubin glucuronide transporters in a rat model of obstructive jaundice. Am. J. Physiol. Gastrointest. Vol.282, G656-G662.

Tiribelli, C.; Lunazzi, G.; Luciani, M.; Panfili, E.; Gazzin, B.; Liut, G.; Sandri, G. \& Sottocasa, G.L. (1978) Isolation of a sulfobromophthalein-binding protein from hepatocyte plasma membrane. Biochem. Biophys. Acta Vol. 531, 105-112.

Tojo A., Sekine T., Nakajima N., Hosoyamada M., Kanai Y., Kimura K. \& Endou H. (1999). Immunohistochemical localization of multispecific renal organic anion transporter 1 in rat kidney. J. Am. Soc. Nephrol. Vol.10, 464-471.

Torres, A.M.; Lunazzi, G.C.; Stremmel, W. \& Tiribelli, C. (1993). Bilitranslocase and sulfobromophthalein/bilirubin-binding protein are both involved in the hepatic uptake of organic anions. Proc. Natl. Acad. Sci. USA Vol.90, 8136-8139.

Torres, A.M. (1997). Mechanistic aspects in the hepatic uptake of long chain free fatty acids, bile acids and non-bile acids cholephilic organic anions. Current Topics in Pharmacology Vol.3, 137-144.

Torres, A.M.; Anzai, N. \& Endou, H. (2008). Renal organic anion transporters: Knowledge from animal models. Current Topics in Pharmacology Vol.12, 45-50.

Torres, A.M. (2008). Renal elimination of organic anions in cholestasis. World Journal of Gastroenterology 14 (43) 6616-6621, (November 2008) ISSN 1007-9327.

Van Aubel, R.A.M.; Peters, J.G.; Masereeuw, R.; Van Os, C.H. \& Russel, F.G.M. (2000). Multidrug resistance protein Mrp2 mediates ATP-dependent transport of classical renal organic anion p-aminohippurate. Am. J. Physiol. Vol.279, F713-F717.

Van Wert, A.L.; Gionfriddo, M.R. \& Sweet, D.H. (2010). Organic anion transporters: Discovery, Pharmacology, Regulation and Roles in Pathophysiology. Biopharm. Drug Dispos. Vol.31, 1-71.

Vanzo, A.;Terdoslavich, M.; Brandoni, A.; Torres, A.M.; Vrhovsek, U.\& Passamonti, S. (2008). Uptake of grape anthocyanins into the rat kidney and the involvement of bilitranslocase. Mol. Nutr. Food Res. Vol.52, 1106-1116.

Villanueva, S.S.M.; Ruiz, M.L.; Soroka, C.J.; Cai, S.H.; Luquita, M.G.; Torres, A.M.; Sánchez Pozzi, E.J.; Pellegrino, J.M.; Boyer, J.L.; Catania, V.A. \& Mottino, A.D. (2006). Hepatic and extrahepatic synthesis and disposition of dinitrophenyl-Sglutathione in bile duct-ligated rats. Drug Metab. Dispos. Vol.34, 1301-1309.

Weiner, I.M.; Glasser, J.E. \& Lack, L. (1964). Renal excretion of bile acids: Taurocholic, glycocholic and cholic acids. Am. J. Physiol. Vol.2076, 964-970.

Wilson, F.A.; Burckhardt, G.; Murer, H.; Rumrich, G. \& Ullrich, K.J. (1981). Sodium-coupled taurocholate transport in the proximal convolution of the rat kidney in vivo and in vitro. J. Clin. Invest. Vol.67, 1141-1150.

Wood, M.; Ananthanarayanan, M.; Jones, B. ; Wooton-Kee, R.; Hoffman, T.; Suchy, F.J. \& Vore M. (2005). Hormonal Regulation of Hepatic Organic Anion Transporting Polypeptides. Mol. Pharmacol. Vol.68, 218-225.

Wright, S.H. \& Dantzler, W.H. (2004). Molecular and cellular physiology of renal organic cation and anion transport. Physiol. Rev. Vol.84, 987-1049. 


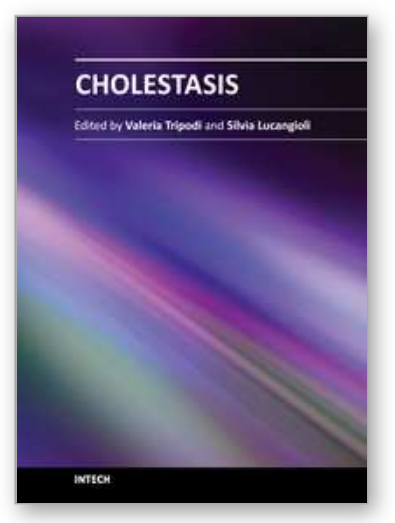

\author{
Cholestasis \\ Edited by Dr Valeria Tripodi
}

ISBN 978-953-51-0043-0

Hard cover, 98 pages

Publisher InTech

Published online 10, February, 2012

Published in print edition February, 2012

This book covers different aspects on the understanding of mechanisms, effects, and management of cholestasis. This unique compendium contains important citations, an invaluable amount of research work, and many applications, which are outstanding resources for clinicians, pharmacists, biochemists, upper-level undergraduate, graduate, and continuing-education students who are dedicated to discovering new knowledge on cholestasis.

\title{
How to reference
}

In order to correctly reference this scholarly work, feel free to copy and paste the following:

Anabel Brandoni and Adriana Mónica Torres (2012). Expression and Function of Renal Organic Anion Transporters in Cholestasis, Cholestasis, Dr Valeria Tripodi (Ed.), ISBN: 978-953-51-0043-0, InTech, Available from: http://www.intechopen.com/books/cholestasis/expression-and-function-of-renal-organic-aniontransporters-in-cholestasis

\section{INTECH}

open science | open minds

\section{InTech Europe}

University Campus STeP Ri

Slavka Krautzeka 83/A

51000 Rijeka, Croatia

Phone: +385 (51) 770447

Fax: +385 (51) 686166

www.intechopen.com

\section{InTech China}

Unit 405, Office Block, Hotel Equatorial Shanghai

No.65, Yan An Road (West), Shanghai, 200040, China 中国上海市延安西路65号上海国际贵都大饭店办公楼 405 单元

Phone: +86-21-62489820

Fax: $+86-21-62489821$ 
(C) 2012 The Author(s). Licensee IntechOpen. This is an open access article distributed under the terms of the Creative Commons Attribution 3.0 License, which permits unrestricted use, distribution, and reproduction in any medium, provided the original work is properly cited. 